\title{
A antropologia e as crianças: da consolidação de um campo de estudos aos seus desdobramentos contemporâneos
}

\section{Anthropology and children: from the consolidation of a field of studies to its contemporary unfoldings}

\author{
Fernanda Cruz Rifiotis' \\ https://orcid.org/0000-0002-7307-2254 \\ frifiotis@gmail.com \\ Fernanda Bittencourt Ribeiro" \\ https://orcid.org/0000-0003-2357-8625 \\ feribeiro2@gmail.com \\ Clarice Cohn"II \\ https://orcid.org/0000-0002-5446-7891 \\ clacohn@gmail.com \\ Patrice Schuch' \\ https://orcid.org/0000-0002-0073-3496 \\ patrice.schuch@gmail.com
}

I Universidade Federal do Rio Grande do Sul - Porto Alegre, RS, Brasil

" Pontifícia Universidade Católica do Rio Grande do Sul - Porto Alegre, RS, Brasil

I" Universidade Federal de São Carlos - São Carlos, SP, Brasil 
O presente número de Horizontes Antropológicos nos convida a pensar na configuração contemporânea do campo da antropologia da criança, o qual é alimentado não só por temáticas múltiplas, mas também pelas contribuições das diferentes disciplinas que o conformam. Tal interdisciplinaridade tanto confere forma a esse campo, cujas articulações teórico-metodológicas são organizadas desde a antropologia, como também coloca desafios e descobertas aos pesquisadores que se dedicam ao universo plural da infância. Em termos de um estado da arte do campo da antropologia da criança, seria possível afirmar, em diálogo com Cohn (2013), que de fato a antropologia dedicada às crianças e às infâncias se consolidou plenamente: a excelência, as possibilidades (metodológicas, analíticas e epistemológicas) e a legitimidade dos estudos realizados nesse campo são reconhecidas nacional e internacionalmente. ${ }^{1}$ Além da participação nos eventos da antropologia através dos grupos de trabalho e mesas-redondas que vêm ocorrendo sistematicamente, cabe destacar os dossiês temáticos que, na última década, contribuíram de forma expressiva para a consolidação de redes de pesquisa e desse campo de estudos no Brasil e na América Latina. ${ }^{2}$ Nesse sentido, não precisamos mais nos preocupar em legitimar esse campo; em "nos fazer ouvir". Mas se avaliarmos a contribuição que temos dado e podemos dar à antropologia, bem como a contribuição que a antropologia tem dado e pode dar ao campo dos estudos das crianças e das infâncias, ainda temos um trabalho pela frente para ampliar interlocuções e entrecruzamentos. E isso não se faz sem desafios e obstáculos.

$\mathrm{Na}$ etnologia indígena, é possível observar algumas dessas dificuldades que ainda são encontradas para tal empreendimento. Nesse campo, argumenta Cohn (2013), os estudos das infâncias indígenas e crianças indígenas vêm

1 Cabe lembrar que o diálogo entre trabalhos desenvolvidos em diversos países da América Latina ainda merece aprofundamento. Congressos internacionais têm demonstrado que o campo da antropologia da criança se consolida em toda a América Latina, mas são poucos os trabalhos comparativos. Poderíamos citar aqui o esforço de pensar as semelhanças e as particularidades do campo no Brasil e na Argentina (Szulc; Cohn, 2012) e o trabalho comparativo de estudos de caso no Brasil, França e Uruguai (Ribeiro, 2016).

2 Ver os dossiês: "Infâncias e crianças: saberes, tecnologias e práticas" (Civitas, 2013, p. 205-380); "Crianças: um enfoque geracional" (Política \& Trabalho, 2015, p. 13-218); "Ser criança no Brasil de hoje” (Latitude, 2016, p. 171-454); “Crianças e infâncias indígenas” (R@u, 2019, p. 10-473); “Entre experiencias y tramas institucionales. Niños, niñas, adolescentes y familias” (Runa, 2019, p. 7-16, 57-272); "La administración de la infancia y la adolescencia hoy" (Cuadernos de Antropología Social, 2021, p. 7-19, 55-169). 
florescendo e revelando muito do que as crianças têm a dizer de seu mundo. Um mundo que, às vezes, só é acessível por meio delas, já que embora conhecido é obliterado pelos adultos (lembrando que esse "obliterado" não significa necessariamente negado, ou recusado, mas às vezes apenas não explicitado). No entanto, os estudos com as crianças têm tido pouco efeito no debate da etnologia indígena em geral - poucos etnólogos leem os estudos sobre as crianças dos povos com os quais trabalham. "Este é um problema real que devemos reconhecer e enfrentar para que nossos estudos não falem apenas para nós mesmos [...] mas ganhem um alcance maior e mais efetivo nos debates da antropologia e no debate sobre o mundo" (Cohn, 2013, p. 223).

O chamado de Cohn (2013) é por maior interlocução, mais entrecruzamentos. Ainda necessitamos ganhar maior abrangência tanto no debate antropológico quanto na intervenção e na atuação pública. E um bom começo para tal empreendimento é reconhecer o que as pesquisas com e sobre crianças têm podido revelar e que nem sempre é visibilizado pelos demais estudos. Esse é o principal compromisso assumido pelos artigos selecionados para este número. A diversidade das temáticas abordadas, nestes textos, permite problematizar as diferentes concepções de "infâncias" e "crianças", além de contribuir para uma inovação teórica, conceitual e metodológica da própria antropologia. Dessa forma, este número nos inspira a pensar nas contribuições dos estudos do campo da antropologia da criança não para o "ser" da antropologia (os contornos e o que constituiu e constitui a "substância" da antropologia), mas o seu "vir a ser" (o que pode a antropologia - a sua potência transformadora) (Cardoso de Oliveira, 2018; Montero, 2004).

\section{Um campo consolidado}

Pensar as contribuições dos estudos do campo da antropologia da criança para o "vir a ser" da antropologia passa pela retomada crítica do percurso de construção e consolidação desse campo. Esse olhar retrospectivo e com inspiração genealógica, ainda que sem a pretensão de esgotar e recobrir a totalidade desse campo, nos permite destacar caminhos possíveis na busca pela ampliação dos entrecruzamentos e interlocuções sugeridas por Cohn (2013), como também faz emergir fios teórico-conceituais cujos desdobramentos contemporâneos 
são problematizados, a partir de uma diversidade de temáticas e abordagens, nos artigos que conformam o presente número.

A proposta de criação de uma antropologia da criança surge de modo explícito, conforme observam Lopes da Silva e Nunes (2002), apenas em 1973 com a introdução provocativa e suscitadora do artigo de Hardman intitulado "Can there be an anthropology of children?" (republicado em Hardman, 2001). A partir desse momento, somam-se ao interesse científico pela infância questões de ordem política em âmbito nacional e internacional, de maneira que começa a proliferar o aparecimento de diferentes organizações não governamentais e movimentos sociais voltados à proteção da infância. No Brasil, ainda que a consolidação desse campo tenha se dado mais recentemente, as crianças estiveram presentes, mesmo que de forma espectral, nos estudos sobre organização social e parentesco, sobre família, rituais, etc. No país, será a exploração do trabalho infantil e o aumento da chamada "delinquência infantil" que não só mobilizarão as atenções nacionais, como também acabarão por transformar as "questões da infância pobre em problema da alçada jurídica" (Lopes da Silva; Nunes, 2002, p. 16). Entretanto, será somente no decorrer dos anos 1990 que a "nascente antropologia da criança" assistirá à emergência de um "novo paradigma" para o estudo da infância. Dentre os princípios de tal paradigma, é importante ressaltar o fato de a infância ser entendida como construção social, não sendo, portanto, uma característica natural nem universal, como variável de análise social, assim como as crianças serem merecedoras de estudos em si mesmas e devem ser vistas como ativas na construção da sua própria vida social.

O reconhecimento das diferentes habilidades das crianças frente aos adultos, assim como também da autonomia e o potencial de decisão destas nos ajudam a pensar em outra categoria de infância não mais universal, mas fundamentalmente relacional. Nessa perspectiva, a infância é concebida como um campo de relações de diferentes ordens, entre grupos etários e de gênero e também entre instituições. No entanto, essa passagem do universal ao relacional remete a uma virada que acompanha o próprio processo de constituição do campo da antropologia da criança e que tem como base teórica central a revisão e os desdobramentos do conceito de socialização. Logo, essa revisão epistemológica propiciada pelo novo paradigma foi central não somente para ampliar o número de pesquisas sobre infância, mas sobretudo para revisitar 
criticamente os paradigmas evolucionistas e funcionalistas que confundiam as etapas da maturidade biológica e o desenvolvimento social.

A observação de diferentes culturas, em especial da infância em sociedades tradicionais, aos poucos nos revelou um universo diferente daquele assumido pelas sociedades ocidentais. A posição teórica, sustentada por um longo tempo por estudos clássicos na antropologia, sobretudo os de orientação funcionalista, de que o desfecho da socialização já era conhecido apontava, como bem lembra Toren (1993), para uma matriz de estudos cujo foco não estava na infância. As crianças, quando apareciam nas etnografias, assumiam papéis secundários nas narrativas e serviam simplesmente para ilustrar as relações entre os adultos em uma dada sociedade. Assim como as mulheres, as crianças eram tomadas enquanto "grupos silenciados", "grupos despercebidos ou evasivos", e como tal demoraram até se tornar objeto válido a ser estudado. Tanto as reflexões propostas pelos evolucionistas do século XIX (os quais estabeleceram estágios do desenvolvimento, considerando o comportamento, pensamento e crenças das crianças como suporte necessário para suas teorias sobre os primitivos) quanto as suscitadas pelos antropólogos psicanalíticos (que viram a gênese da personalidade individual e também um todo da personalidade cultural corporificada na infância) não revelaram ou marcaram o começo da antropologia da criança. $O$ uso possível da criança em campo pode ser visto somente em 1929, no trabalho clássico de Margaret Mead sobre a infância em Samoa. A autora, que sempre manteve o compromisso de contemplar aspectos da infância e adolescência em suas etnografias, ao final de sua carreira, como lembram Lopes da Silva e Nunes (2002), ainda se questionava sobre o pouco interesse dos antropólogos por tais questões.

Na sua experiência junto aos samoanos, Mead observou que toda civilização primitiva e, inclusive, outras modernas diferiam da sociedade norte-americana pelo número de escolhas que são permitidas a cada indivíduo. Ao contrário das crianças norte-americanas que se confrontam com diversos códigos morais, para os samoanos, o grau de individualização é mais reduzido e eles não se deparam com eleições contraditórias que os obriguem a rechaçar as normas do grupo social. Isso porque as relações de parentesco não são postas a priori, mas sim emergem das interações cotidianas. A criança samoana, como observa Mead (1961), aprende, desde muito cedo, que o seu mundo está composto por uma hierarquia de adultos (masculinos e femininos) em todos os quais pode confiar e aos quais deve obediência. 
Mead também chamou atenção para o fato de que a inteligibilidade da vida de uma criança na sociedade norte-americana só pode ser medida em função da conduta de outras crianças, enquanto para a criança samoana, os atos de trabalho ou de diversão são medidos em função de toda a sua comunidade. Isso significa que cada aspecto da conduta é honrado em razão da sua relação verificada com o único modelo que a criança conhece: a vida de uma aldeia samoana. Ainda que a autora confira um certo isolamento à infância samoana, é interessante perceber que as ações das crianças são pensadas no âmbito das relações sociais mais amplas, o que nos fornece pistas para pensar na importância do papel social que estas assumem na manutenção da organização social. Além disso, salvo as limitações postas pelo comparativo entre as duas sociedades, a etnografia empreendida por Mead (1961) nos permite observar como a infância, por ser experimentada de diferentes maneiras, em diferentes culturas, pode ser compreendida não em sua universalidade, mas enquanto categoria a ser construída socialmente.

No lugar da convencional ênfase na socialização, que por vezes tem trivializado o status social da infância, Enid Schildkrout (1978) buscou no cotidiano da sociedade hausa elementos para pensar a interação entre crianças e adultos, a autonomia do mundo das crianças e a relação entre distintas definições culturais na infância e fatores socioeconômicos. Entre os hausa, as crianças ocupam um papel central na articulação das relações sociais, de maneira que os papéis sociais não poderiam ser definidos e mantidos como eles são sem que as crianças performem certos papéis que são ao mesmo tempo distintos e complementares aos dos adultos. As crianças são cruciais na manutenção da instituição do purdah, em certas classes econômicas e na definição dos papéis sexuais, tanto que a mudança no papel das crianças implica alterações não só nas próprias crianças, mas em toda a estrutura da sociedade hausa. Há, por exemplo, um número limitado de atividades econômicas abertas às mulheres no purdah que não requerem a assistência das crianças.

Assim como em Schildkrout, a reflexão sobre a autonomia do universo infantil também aparece em Hardman (2001), em especial, na sua proposta de estudar as crianças "nos seus próprios termos" e não simplesmente como receptáculos dos ensinamentos dos adultos. Diante da perspectiva de psicólogos e antropólogos funcionalistas, os quais optaram por pensar o desenvolvimento infantil em termos diacrônicos, reforçando a ideia da infância como 
algo que não é, exceto em termos de seu desenvolvimento, Hardman (2001, p. 504, tradução nossa) optou pela perspectiva sincrônica, nos desafiando a pensar na possível existência de uma autorregulação na infância, ou seja, um "mundo autônomo que não necessariamente reflete um desenvolvimento prematuro da cultura dos adultos". Esse desafio passa pela revisão da concepção de socialização mencionada anteriormente, que é tensionada em função do reconhecimento de que as crianças aprendem entre si e de que há contextos que reservam papéis sociais às crianças.

O reconhecimento da agência infantil e da possibilidade de as crianças atuarem como mediadores importantes nas relações entre os adultos foi ganhando visibilidade à medida que as/os pesquisadoras/es conseguiram desconstruir a ideia de infância como fenômeno universal. Uma vez que a infância é desatrelada da concepção de desenvolvimento centrada exclusivamente em questões biológicas (distribuídas em etapas, as quais precisam ser cumpridas e identificadas em qualquer criança, independentemente do seu contexto social, cultural e econômico), as pesquisas que reconhecem a infância como categoria construída socialmente acabam por ganhar visibilidade. Assim, foi possível problematizar a concepção de infância como etapa de "preparação" e de entretenimento, a qual tinha como pressuposto o fato de as crianças serem tomadas como estáticas, assumindo uma única função que seria a de receber passivamente as pautas dos adultos.

Logo, o processo de desontologização da categoria de infância e o reconhecimento do seu caráter construído e, portanto, não estático e tampouco homogêneo, nos permitiram falar em "infâncias", no plural, como forma de atentar para objetos de estudo dinâmicos, flexíveis e autônomos. Autonomia esta que permitiu às/aos pesquisadoras/es estudar as crianças "por si mesmas" ou "em seus próprios termos" e não mais como futuros adultos. Se existem devires que inspiram tais infâncias, estes apontam para um "vir a tornar-se" que é permanente e não tem necessariamente como ponto máximo a vida adulta. É possível, portanto, pensar na infância em termos de "possibilidades", sem que estas se refiram simplesmente a uma espécie de preparação para a vida adulta. Todos esses devires, próprios da infância, põem em xeque, como bem lembra Toren (1993), a concepção de que as crianças simplesmente se tornam o que os adultos já são. "Parece que as crianças e os adultos, em grande medida, são vistos como ontologicamente diferentes, habitantes de mundos que não devem correr 
o risco de misturar-se" (Pires, 2007, p. 44-45) e, além disso, quando existe contato, o mundo infantil estaria organizado apenas para cumprir as demandas do mundo adulto, onde são efetivamente criadas as regras, os valores e aprendizagens socialmente aceitas. Dessa forma, a pretensa separação entre mundo adulto e infantil só acaba por alimentar e reificar dicotomias tão conhecidas e combatidas no campo da antropologia como a posta na relação nós-eles. Nesse caso o universo infantil será o "outro" a ser caracterizado e narrado pela perspectiva do universo adulto.

Nesses termos, pleitear a autonomia, em termos epistemológicos, do universo infantil em relação ao universo adulto significa reconhecer tais universos em relação de complementariedade. Claro está que essa complementação nem sempre se dará de forma pacífica e, portanto, sem tensões, até mesmo porque a interdependência que se deseja não se coloca apenas para que se possa pensar um universo em comparação ao outro, como forma de estabelecer qual é mais completo ou melhor, mas, sim, permite conhecer melhor cada universo e consequentemente colocá-los em perspectiva. "Isso significa que o universo infantil não é mais visto como experiência parcial do mundo social, no sentido de conter conhecimentos menos completos; ele é visto como capaz de construir uma apreensão que é diferenciada e relevante" (Cohn, 2002, p. 233). O reconhecimento de que as crianças criam e negociam suas próprias regras e hierarquias nos diz muito não só sobre a criatividade desses sujeitos e sobre formas alternativas de aprendizagem, como também nos informa sobre a possibilidade de tensionar as convenções próprias do mundo adulto.

O desafio de pensar a autonomia do universo infantil ainda é maior quando nos deparamos com questões de ordem metodológica que têm se colocado nesse campo de estudos. Questões como as postas por Pires (2007), "em que medida estudar crianças requer métodos e técnicas especiais?", "talvez devêssemos continuar aplicando os mesmos instrumentos empregados no estudo dos adultos?", "qual o lugar do pesquisador adulto na pesquisa com crianças?", nos têm levado a pensar nos esforços para sair dessa posição e nos problemas decorrentes de tal desafio. As experiências em campo têm nos mostrado que a etnografia, tomada enquanto movimento epistemológico privilegiado para pesquisar crianças, é revestida de estratégias capazes de dar conta do dinamismo do universo infantil. Ou seja, estar atento para tais recursos e para as próprias demandas das crianças em relação à pesquisa tem permitido, às pesquisadoras 
e pesquisadores, tanto desconstruir categorias adultocentradas, as quais, além de não darem conta da especificidade do universo infantil, estão focadas nas expectativas dos adultos em relação às crianças, como especialmente pensar que tanto as brincadeiras como os jogos são espaços reveladores do potencial de agência desses sujeitos (Pires, 2007).

\section{Desdobramentos contemporâneos}

Tendo em vista essa revisão, com ares genealógicos, do campo da antropologia da criança, seria possível identificar pistas acerca das contribuições da antropologia da e com crianças, pensando no "vir a ser" da própria antropologia. Ao tensionar o conceito de socialização, as pesquisas desenvolvidas nesse campo têm apontado para a desconstrução da categoria "infância universal" (sobretudo em função da revisão e dos desdobramentos do conceito de socialização) para concebê-la enquanto relacional. Uma vez que reconhecemos a criança como agente, esta deixa de ser dependente da trama de relações que supostamente a constituiria e passa a ser vista a partir das suas ações, em especial aquelas que são travadas nos interstícios das convenções e negociações estabelecidas pelos diferentes atores e instituições. Nesse sentido, a criança passa a ser percebida como inseparável das diversas relações que conformam a trama social da sua existência (Fonseca, 2006; Strathern, 2006).

Ao propor a desontologização das categorias "infância" e "criança", a antropologia da criança permite repensar outras tantas noções, como a de parentesco, família, instituições, etc. Acompanha os debates mais contemporâneos da antropologia ao trazer para o primeiro plano das análises o potencial de agência das crianças e o papel de mediadoras que estas assumem nos mais diversificados contextos sociais (Fonseca, 2006; Tassinari, 2007). Permite também problematizar a relação entre universo adulto e infantil e, consequentemente, as ações das crianças no âmbito de relações mais amplas, visibilizando inclusive as relações entre as próprias crianças e não somente em função das ações dos adultos. $\mathrm{O}$ reconhecimento da autonomia do universo infantil nos leva a reconhecer a presença de outras temporalidades e formas de estar no mundo e a criatividade desses sujeitos. Ou seja, as contribuições desse campo, consolidado e em processo de consolidação, apontam para a constatação de que 
as pesquisas antropológicas podem ser enriquecidas ao considerarem o ponto de vista das crianças acerca das suas experiências no mundo: visibilizando aquilo que nem sempre é objeto de estudo em pesquisas focadas nos adultos. Alinhados com esse argumento, os artigos reunidos neste número abrem possibilidades que vão além da pluralização da noção de infância. Eles permitem sugerir a hipótese de que a inclusão das crianças nas pesquisas antropológicas pode acrescentar perspectivas conceituais e analíticas aos diversos campos de estudos da disciplina. Abordadas a partir de suas práticas, as crianças dos artigos deste número de Horizontes Antropológicos vendem, pedem e cuidam, estão em conflito com as normas de gênero, ocupam terra e brincam, têm autoridade ritual, pensam e desenham a cidade, migram, aprendem, são artistas.

Em termos metodológicos e epistemológicos, cabe observar então que essas etnografias que captam as participações ativas das crianças nas diversas dimensões da vida social são elas mesmas plurais e estão em diálogo com diferentes campos de estudo: do trabalho e da economia, do gênero, da família e do parentesco, dos movimentos sociais, da religião, da cidade, das migrações, da aprendizagem, das artes e muitos outros. Ao não reiterar que a ludicidade, as brincadeiras ou os desenhos sejam restritos ao universo infantil, as experimentações e estratégias usadas nas pesquisas com crianças aqui apresentadas podem contribuir com reinvenções da própria etnografia. Por outro lado, interrogar o pressuposto de que a pesquisa com crianças demanda habilidades específicas pode contribuir para ampliar a participação das crianças nas pesquisas antropológicas de um modo geral.

Dito isso, os artigos que conformam o presente número temático contribuem ao menos em três frentes para os debates contemporâneos da antropologia (o vir a ser desta). A primeira frente está relacionada às epistemologias e metodologias das pesquisas do campo da antropologia da criança, abordadas nos artigos de Clarice Cohn, de Antonella Tassinari e de Emilene Leite de Sousa e Flávia Ferreira Pires, e também nas discussões sobre agência e apropriação presentes nos textos de Mariana García Palacios e Andrea Szulc e de Laura Frasco Zuker, Rocío Fatyass e Valeria Llobet. A segunda frente diz respeito às reflexões sobre aprendizagens e brincadeiras, nos textos de Chantal Medaets, de Paula Bessa Braz, de Gustavo Belisário e de Beatriz Soares Gonçalves. A terceira frente tematiza questões de diversidades/diferenças (através das relações de gênero, das experiências religiosas e de migração), como nos textos de 
Arthur Leonardo Costa Novo, de Leandro Piñeyro e Pilar Uriarte Bálsamo e de Christiane Rocha Falcão. Esses 12 artigos reforçam, de forma mais ou menos direta, a ideia de que a cultura é inventada e aprendida e que o papel das crianças nesse processo é incontornável, são elas que, como bem lembra Cohn em seu artigo, frequentemente recebem e acompanham os etnólogos em campo, tornando possível o acesso e a compreensão de outros mundos. A observação de suas práticas nos permite tensionar dicotomias tais como biológico/social, universal/relacional, local/estrangeiro, masculino/feminino, atividade/passividade, etc. Suas brincadeiras são "boas para pensar" as relações entre a antropologia da criança e outros campos da disciplina antropológica. Tais brincadeiras, que não são exclusivas do universo infantil, também nos lembram como crianças e adultos são produzidos uns a partir dos outros. E que em certos espaços, como nos rituais, os ogãs-crianças possuem autoridade ritual sobre adultos e crianças, sinalizando a relativização da noção de criança e consequentemente das formas pelas quais nos acostumamos a conceber e a operar hierarquias e regras.

A ampliação da concepção de criança, em função das experiências de gestação, parto e puerpério, nos convida à problematização de noções caras à antropologia, como as de pessoa, corpo e parentesco. As aprendizagens, longe de seguirem lógicas formais e universalizantes, são produto de práticas e concepções locais. E, nesse sentido, as crianças, comumente pensadas no lugar de aprendizes, se tornam mestras, nos ensinando sobre contingências e agenciamentos múltiplos. Os desenhos, tomados enquanto técnica importante de pesquisas com crianças, tensionam a ideia de representação, trazendo para o primeiro plano das reflexões a "criação", os modos de criar, de se colocar no mundo e de inventar novas possibilidades de vida para que as políticas públicas também possam ser outras, múltiplas e atentas às particularidades dos sujeitos.

\section{Epistemologias e metodologias de pesquisa}

Iniciamos esse número com o artigo de Clarice Cohn intitulado "O que as crianças indígenas têm a nos ensinar? $\mathrm{O}$ encontro da etnologia indígena e da antropologia da criança", que nos inspira a pensar nos desafios postos pelo encontro entre antropologia da criança e a etnologia indígena. A partir de uma revisão de fôlego dos estudos sobre crianças indígenas no Brasil produzidos nos últimos 
tempos, a autora identifica uma clivagem sistemática: ou o texto etnológico foca nas crianças ou não as tem como interlocutores. Diante de tal diagnóstico, a autora propõe uma mudança de postura que passa pelo reconhecimento das crianças não como figurantes nesses trabalhos, mas como atores centrais que podem contribuir e ampliar os debates antropológicos mais contemporâneos. O que a antropologia da criança, ou da infância, nos tem ensinado, lembra Cohn, é que a centralidade das crianças nas etnografias passa pelo reconhecimento de que essas são membros plenos das sociedades e também plenamente competentes nas culturas em que vivem. Se toda cultura é inventada e aprendida, cabe a nós atentarmos, segundo a autora, para a parte importante reservada às crianças nesse processo. Não é possível compreender e apreender as infâncias indígenas sem uma boa etnologia, assim como não teremos uma boa etnologia, em termos teóricos e epistemológicos, enquanto insistirmos em não olhar mais atentamente para as crianças e as suas próprias concepções de infância, ressalta Cohn. Instigante pensar, seguindo a autora, como uma reflexão sobre as crianças e a inserção destas nos debates mais amplos da própria etnologia pode colaborar na construção de uma antropologia ampliada. A fim de dar conta das novas formulações da etnologia, há que se considerar, seguindo os argumentos da autora, para além das concepções indígenas de infância, os processos de fazer pessoas e aparentamento, levando em consideração os compósitos múltiplos das crianças.

Na sequência, o artigo "Entendeu ou quer que eu desenhe? Os desenhos na pesquisa com crianças e sua inserção nos textos antropológicos", de Emilene Leite de Sousa e Flávia Ferreira Pires, aborda questões epistemológicas e metodológicas mais abrangentes para o campo de estudos da antropologia da criança. As autoras analisam a utilização dos desenhos produzidos por crianças em pesquisas antropológicas, a partir de dois argumentos. O primeiro seria o reconhecimento da legitimidade dos desenhos como técnica de pesquisa com crianças (sem estabelecer hierarquias em relação a outras técnicas), e o segundo chama atenção para a necessária visibilidade do processo de produção de tais desenhos nas pesquisas. Ao percorrerem criticamente as formas pelas quais os desenhos têm sido tratados/pensados em pesquisas antropológicas clássicas e contemporâneas, em âmbito nacional e internacional, as autoras constatam que, embora não seja necessário criar novos métodos para dar conta do ponto de vista das crianças, é fundamental reconhecermos o potencial e a eficácia de métodos e técnicas, tais como os desenhos, no trabalho com crianças. 
Não sendo apenas uma representação, mas sobretudo criação, os desenhos têm o potencial de dar vida, segundo as autoras, a uma experiência que até então não existia. Ao desenhar, as crianças constroem sentidos sobre a realidade e por isso mesmo os desenhos são um modo privilegiado de acessar as percepções dos sujeitos. As autoras ressaltam que, mais do que o produto final, o que conta para as crianças é o processo de criação, o qual por vezes acaba sendo omitido ou ganhando o segundo plano nas etnografias. Seguindo tal perspectiva, as autoras ressaltam a possibilidade de articulação dos desenhos com outras estratégias metodológicas, sobretudo a observação participante, uma vez que parte importante do processo de produção dos desenhos são as narrativas que as crianças tecem sobre estes. Os desenhos, ressaltam as autoras, permitem uma maior participação das crianças nas pesquisas, tornando-as coautoras do fazer etnográfico. E, nesse processo, as autoras nos convidam a pensar que mais do que um caminho para se aproximar das crianças em campo, as técnicas, como os desenhos, são potentes no sentido de revelarem aquilo que o corpo, os gestos e a própria retórica eventualmente deixam escapar.

O artigo "A 'mãe do corpo': conhecimentos das mulheres Karipuna e Galibi-Marworno sobre gestação, parto e puerpério", de Antonella Tassinari, é de fundamental importância neste número por nos permitir, acompanhando as noções indígenas de infância, nesse caso dos Karipuna e Galibi-Marworno do Amapá, ampliar a ideia mesmo de criança a ser tratada em pesquisas no campo da antropologia da criança. A partir de uma etnografia muito rica, a autora discute a gestação, o parto, a puericultura, demonstrando que a criança já o é muito antes do recorte, muitas vezes assumido inadvertidamente, em extensão a uma ideia ocidental, seja biomédica, religiosa, etc., que marca o ponto de inflexão no nascimento. A agência das crianças aparece no texto desde antes desse acontecimento, mas principalmente nele. Questões clássicas da etnologia, como a formação do corpo e a construção do parentesco, assim como os conhecimentos genderizados - os conhecimentos femininos e em especial das parteiras, mais ou menos interligados com práticas biomédicas - são tratados de modo inovador e que, portanto, muito tem a contribuir com o campo.

A partir de reflexões sobre o conceito de apropriação e de agência infantil, Mariana García Palacios e Andrea Szulc escrevem o artigo intitulado "Entre apropiaciones, resistencias e intentos de conversión religiosa. Niños y niñas indígenas ante propuestas escolares católicas en Argentina". O texto investiga 
a recepção de propostas de distintas congregações da igreja católica, feita por crianças mapuches na província de Neuquén e de crianças tobas/qom em Buenos Aires e Chaco. Percorrendo o histórico de intervenções dessas congregações católicas, marcado pelo interesse na assimilação cultural na "civilização" das crianças indígenas, as autoras salientam o quanto tais empreendimentos compreendem a infância como a fase ideal para a renúncia à cultura autóctone dos indígenas e sua conversão ao catolicismo. Isso se dá pelo acionamento de uma noção de infância que a liga à inocência, bondade e maleabilidade. De acordo com García Palacios e Szulc, em que pese tal similaridade, entre os mapuches os cristãos salesianos empregaram propostas abertamente sincréticas, ao passo que entre os tobas/qom a ênfase se deu através das práticas de caridade; nos dois casos, entretanto, a agência infantil foi dada em acordo com as estratégias variadas de governo, o que a posiciona como um elemento contextual e histórico.

A preocupação com a noção de uma "agência situada" é central também no artigo de Laura Frasco Zuker, Rocío Fatyass e Valeria Llobet, intitulado "Agencia infantil situada. Un análisis desde las experiencias de niñas y niños que trabajan en contextos de desigualdad social en Argentina". O texto preocupa-se em realizar uma análise comparativa de experiências de investigação com crianças que vendem, pedem e cuidam nas províncias argentinas de Córdoba e Misiones. Na interseção das problematizações das relações entre trabalho e desigualdades, as autoras propõem que as análises sobre o tema devam não apenas descrever as variadas atividades de trabalho realizadas por crianças, mas também se perguntar sobre as suas condições de produção e realização, levando-se em conta também o caráter histórico e socialmente constituído das categorias "trabalho" e "infância". O artigo realiza um diálogo com o campo de debates sobre trabalho, cuidado e infância em contextos de desigualdade social, afirmando o caráter situado da agência e o sentido contextual da participação de meninas e meninos nas atividades produtivas. A partir de uma potente etnografia, as autoras argumentam que as crianças constroem, mediante usos específicos das tarefas produtivas e reprodutivas, diferenças morais e hierarquias sociais intra e entre grupos. Como explicitam: "Recursos materiales y simbólicos, distinciones y jerarquías morales y sociales son transformadas, producidas o reforzadas por las tareas de cuidado y reproducción." 


\section{Aprendizagens e brincadeiras}

O artigo "A aprendizagem vista pela antropologia: reflexões a partir de uma etnografia na região do Baixo Tapajós", de Chantal Medaets, é uma importante contribuição para o debate já antigo sobre como a antropologia pode contribuir para uma melhor compreensão da aprendizagem. Com uma extensa etnografia na região do Baixo Tapajós, ela demonstra que é exatamente a etnografia que permite que se veja a diversidade de modos de ensino e aprendizagem. Sua demonstração é desenvolvida no texto em diálogo com esses modos, evidenciando que a aprendizagem não precisa vir com o ensino ou a instrução, mas, como nesse caso, exatamente ao contrário - as crianças frequentemente lhe afirmavam, aliás, terem aprendido sozinhas. Práticas centradas nas crianças, de observação, de interesse, de se acostumar e garantir e se garantir, como aprende e nos ensina a autora, nos permitem pensar a aprendizagem - como ela propõe - a partir de processos e concepção locais e, portanto, em oposição a um pressuposto de universalidade, contribuindo assim com um aprofundamento e uma ampliação da noção mesma de aprendizagem.

O artigo "Vem! É só segurar o violino assim e olhar pra frente' - o que as crianças podem nos ensinar sobre fazer música (e fazer antropologia)?", de Paula Bessa Braz, nos apresenta, por meio de uma cuidadosa etnografia em que a pesquisadora utilizou diversas metodologias e mídias e estabeleceu relações múltiplas com as crianças, uma situação valiosa que nos permite também rever muitos dos estereótipos que marcam as infâncias. Tratando de crianças que se organizam - e organizam um espaço formativo - para ensinar outras crianças a tocar instrumentos sinfônicos, normalmente relacionados à música dita erudita, o texto nos permite essa ampla inversão: o das crianças aprendizes que são também mestras, e o das crianças de periferia que se dedicam a uma musicalidade normalmente relacionada à não periferia, à elite. A capacidade de organização, articulação e gestão das crianças - junto a suas famílias - está sempre presente em suas preparações para figurar como instrumentistas e implementar projetos, assim como em seu papel formativo. $O$ texto traz ao debate deste número essa outra amplitude do campo em uma empreitada verdadeiramente antropológica, em que os estereótipos são desafiados em diálogo com o campo e, mais precisamente, com as crianças. 
Gustavo Belisário, no artigo "Café-com-leite, piques e gigantes: brincando no acampamento Canaã (MST - DF)", traz uma instigante análise que propõe a flexibilização dos limites entre a antropologia da criança e os demais campos da antropologia. $\mathrm{O}$ autor argumenta que pensar as brincadeiras a partir de sua endogenia pode mudar perspectivas da disciplina antropológica. A etnografia realizada num acampamento do MST, e que se estendeu a outros espaços, coloca em movimento a segmentação adultos e crianças e a própria noção de brincadeira como algo restrito ao universo infantil. Através de uma cena inspiradora, recuperada no texto, e na qual três crianças iorubás brincam de antropólogo, o autor situa a própria antropologia como um jogo de deslocamentos e movimentações de ideias, conceitos e sentimentos em analogia com o brincar que também coloca em jogo essas atividades da mente. As brincadeiras de queimada, pique-esconde e dominó, cujas cenas são ficcionadas pelo autor, são o contexto a partir do qual os significados conceituais de café-com-leite, guardar caixão e licença são por ele levados a sério como modos de pensar e agir. A abordagem proposta no artigo pode ser lida como uma resposta ao risco de reificação das categorias adulto e criança como designações de uma alteridade fundamental. Se, por um lado, a antropologia da criança remete a essa segmentação, por outro, como o próprio artigo evidencia, as produções desse campo, ao problematizarem a noção de criança universal, abrem a possibilidade de perguntar sobre a universalidade do ser adulto. Ao incorporar os adultos nessa pesquisa com crianças, vê-se a possibilidade de pesquisar as diferentes concepções e formas de ser adulto e explorar, contextual e relacionalmente, os modos como adultos e crianças são produzidos uns a partir dos outros. $\mathrm{O}$ artigo suscita pensar que os conceitos deleuzianos de limite-tensão e limite-contorno mobilizados pelo autor para a análise das brincadeiras poderiam servir também para pensar sobre as relações entre a antropologia da criança e os outros campos da disciplina antropológica, interrogando o alcance da primeira em relação aos contornos que delimitam a própria antropologia.

No artigo "A cidade e as crianças: desenhos e caminhos a partir do Morro do Estado (Niterói, RJ)", Beatriz Soares Gonçalves coloca em diálogo os campos de estudo da antropologia urbana, da antropologia da criança e das políticas públicas para a cidade. Os desenhos de crianças a partir de seis anos de idade, realizados no âmbito de um projeto que desenvolve atividades no contraturno escolar, são o suporte para as reflexões da autora acerca da sua posição no 
trabalho de campo, das potencialidades do desenho na pesquisa etnográfica e da contribuição das crianças para o desenvolvimento de políticas públicas. Para a pesquisa e na análise dos dados, os desenhos desempenham múltiplos papéis atuando ora como mediadores das relações da pesquisadora com as crianças, ora como um recurso através do qual foi possível aproximar os conhecimentos, memórias e ideias que elas têm sobre o bairro e a cidade em que vivem. Os desenhos apresentados no artigo não são abordados em si mesmos, mas contextualizados como uma prática proposta no Projeto Socioeducativo em que a autora atua como educadora, e lidos em perspectiva com os dados de sua etnografia no bairro. Na leitura do texto, ainda que essa intenção não seja explicitada, alguns conjuntos de desenhos funcionam também como um recurso através do qual nosso olhar é conduzido pela perspectiva das crianças. As escadas e os becos desenhados, quando colocados lado a lado, produzem o efeito de contextualizar a afirmação das crianças que, para surpresa da pesquisadora, dizem não morar numa rua. Eles servem também para facilitar a troca de ideias e para imaginar o futuro. Ao serem provocadas a desenhar como gostariam que o bairro fosse, a imaginação das crianças dá ideias para um planejamento urbano que favoreça as relações de amizade, os jogos e brincadeiras, em espaços arborizados e pacíficos. $\mathrm{O}$ artigo ilustra bem o argumento de que as pesquisas com crianças, ao contrário de fecharem-se sobre si mesmas, apresentam potenciais de experimentação metodológica, de abertura de diálogos com outras antropologias, como a antropologia urbana, e de participação no debate acerca da cidade e das políticas públicas.

\section{Diversidades e diferenças}

Arthur Leonardo Costa Novo, no artigo “Mãe, Maria nunca existiu! Me chama de João?' Uma análise etnográfica das relações de família e medicalização nas experiências de 'crianças trans'", aborda o entrelaçamento entre as explicações e práticas das ciências médico-psi e a reorganização das relações familiares num percurso de transição de gênero. A partir da interlocução com Penélope, uma mulher de camada média, psicóloga e mãe de Lucas, um "menino trans", o autor coloca em relevo o modo como a busca de explicação e de alternativas terapêuticas para o filho mobiliza valores e concepções contemporâneas 
de família e infância que se configuram em relações complexas de medicalização e tutela. Por um lado, a ênfase afetiva na definição do lugar da família, assim como o reconhecimento da criança como um sujeito de agência, amparam as decisões da mãe e mesmo a renegociação de sua autoridade diante do conflito de gênero vivido pelo filho. Na relação com os saberes médicos, que figuram no artigo como dinâmicos e em estreita relação com os parâmetros legais de intervenção, observa-se a sutileza com que Penélope apoia-se nas alternativas existentes, sem necessariamente aderir a um discurso patologizante que não se revela hegemônico nem mesmo nas posições médicas em relação às demandas de intervenção. Destaca-se também a condição de tutela que posiciona Lucas enquanto criança nas relações familiares e com profissionais de saúde, estendendo o alcance e a autoridade médico-psi para diferentes esferas no cotidiano da família. As nuances trazidas pela análise permitem observar que essa condição tutelar não implica total submissão: a determinação de Lucas em relação ao seu conflito identitário é o que sustenta as atitudes da mãe que passa a apoiá-lo, assim como a legitimidade e o vocabulário explicativo da medicina e suas práticas terapêuticas colaboram para que a mãe sustente suas posições nas relações familiares e com as demais instituições. Ao debruçar-se sobre as tensões e conflitos que atravessam essas relações, o artigo demonstra como a transição de Lucas implica mudanças profundas também para sua mãe, que constrói uma ética determinada a fazer com que a vida do filho seja possível. Valores, emoções e concepções de infância, família e moralidade atuam em diferentes níveis evidenciando o caráter ativo dessas concepções nas experiências de crianças e familiares engajados em processos transicionais com relação às normas de gênero.

O artigo "Viene, está acá y tâ'. Una aproximación a las vivencias de niños y niñas en torno a la migración en una escuela de Montevideo", de Leandro Piñeyro e Pilar Uriarte Bálsamo, resulta de uma experiência de trabalho de mais de três anos junto a crianças da escola Portugal, de Montevidéu, que acolhe uma alta porcentagem de população migrante. Ao analisar as formas como as crianças da escola vivenciam os fenômenos migratórios, o artigo confere visibilidade aos sentidos que têm sido silenciados nos estudos sobre migração, tradicionalmente focados nas narrativas dos adultos. Ao longo do texto, os autores nos conduzem através de uma reflexão que articula migração e escola e que tem sido potencializada sobretudo na última década, quando o Uruguai 
começa a receber população migrante proveniente de diversos países latino-americanos. Tendo em vista que a escola pública tem recebido e executado o mandado de "transformar" em uruguaios a descendência do grupo heterogêneo de migrantes que conformam a base da população do país, é instigante a experiência dos estudantes de uma escola considerada como modelo pelas autoridades do sistema educativo uruguaio. No lugar de exaltar uma possível generalização das reflexões em torno da forma como a migração é trabalhada na escola Portugal, os autores se concentram nas especificidades de uma experiência escolar em que a diversidade e as formas de interculturalidade se colocam como possibilidades abertas e em permanente construção e, portanto, para além da já desgastada dicotomia local/estrangeiro. Dentre tais especificidades, chama atenção a forma criativa e inspiradora de empreender a análise: se trata de um processo simultâneo de intervenção e investigação tornado possível a partir de uma oficina sobre antropologia, a qual, além de conformar as propostas educativas do centro, se constituiu enquanto dispositivo metodológico para a pesquisa. O rico material etnográfico que dá vida ao artigo nos convida a pensar na infância como disputa de sentidos, como fato político, e permite desconstruir/ressignificar as fronteiras e as inscrições nacionais sem, no entanto, apagá-las. As experiências das crianças da escola Portugal propõem alternativas às formas de significar a migração e vincular-se à diferença e funcionam como um chamado a outras formas de conceber a própria antropologia.

Tendo como base uma longa experiência de pesquisa sobre candomblé ketu, Christiane Rocha Falcão, em seu artigo "A idade do santo. Crianças e autoridade ritual no candomblé", coloca em questão a relativização da noção social e biológica da "criança". Pesquisando com crianças no terreiro de candomblé ketu Ilê Axé Omin Mafé em Sergipe, o artigo discute o lugar ritual do ogã-criança, segundo a teoria nativa, e sua relativa autoridade ritual sobre adultos e crianças. Argumenta que o lugar social da criança não é necessariamente o lugar social de alguém com pouca idade, e que essas duas noções são complementares e negociadas. Focando-se nos processos de aprendizagem e transmissão do conhecimento religioso, a autora destaca que é através da experiência perceptiva que os ogãs-crianças compreendem o seu estar no mundo e são esses esquemas conceituais que permitem que as crianças percebam o mundo natural e social como um todo orgânico. Sobre a autoridade ritual dos ogãs-crianças, a autora conclui que tal autoridade "parece contribuir para o projeto 
de reformulação dos limites entre o que é natural e o que é sobrenatural, entre o que é socialmente 'estabelecido' e o que possibilita o ritual".

Muito do que se tem dito nesta apresentação sobre a formação do campo é testemunhado e ilustrado pelo desenho escolhido para a capa deste número. O desenho coletivo de meninos xikrin do Bacajá, realizado na década de 1990 e ofertado à antropóloga Clarice Cohn, nos fala muito sobre metodologia e sobre os fazeres das crianças. Experimento metodológico do início das pesquisas com crianças indígenas no Brasil, a partir da sugestão de Lux Vidal de levar a campo lápis de cor e de cera e folhas de papel A4, os desenhos se revelaram importante meio de compreensão de como as crianças veem seu mundo e as relações que neles estabelecem. Mais que isso, revelou à pesquisadora os modos de se relacionar e organizar as atividades das crianças xikrin. Feitos coletivamente, levando a entusiasmados debates sobre temas, cores, formas de desenhar, em um uso muito livre do suporte do papel, foram também realizados a partir de uma organização de atividades e de coletivos feita pelas crianças. À antropóloga só restava fornecer o material demandado quando as crianças decidiam dedicar o seu tempo ao desenho - e que foram na época muitas horas diárias, uma atividade frequente e prazerosa. Dar os desenhos feitos à pesquisadora foi também uma iniciativa das próprias crianças - respeitando o jeito dos não indígenas de colecionar registros e valorizar o papel, pareceu-lhes o destino ideal, permitindo a montagem de uma verdadeira coleção com motivos diversos. No desenho, é possível identificar temas fundamentais aos Xikrin vistos pelos olhos das crianças. As aldeias circulares, típicas dos povos jê, como são os Xikrin, são vistas em um plano aéreo. Roberto DaMatta (1976) já havia indicado pelos desenhos de homens adultos apinajé que, mesmo com a vivência à época em uma aldeia feita em formato de rua, como se diz, ou seja, com casas paralelas, a aldeia foi desenhada por eles nessa mesma perspectiva aérea, a partir da única imagem que lhes era possível da aldeia, circular. No desenho das crianças xikrin, tal perspectiva acerca das aldeias não só é permitida como é sobretudo enriquecida pelo avião que a alude, na medida em que este compõe a imagem com as novas tecnologias que fascinam as crianças. Mais que isso, elas povoam todo o desenho com a presença humana. O pátio, lugar das festas mas também tomado cotidianamente pelas crianças brincando, está povoado; assim também, a pista de pouso do avião está sendo usada como campo de futebol e brincadeiras. Relações de parentesco, rituais, brincadeiras das crianças entre 
si e com as tecnologias não indígenas estão retratadas neste pequeno excerto comentado do desenho, que se complementa no papel com outra aldeia, com um cubo caracteristicamente aprendido na escola, com motivos diversos. Só temos a agradecer a essas crianças - hoje homens, pais e avôs - o (literal) presente do desenho com toda sua riqueza.

Em seu conjunto, portanto, este número vem, para além de reafirmar a importância e a consolidação da antropologia feita com e sobre crianças, provocar e instigar debates mais ampliados, e esperamos que venha a ter efeitos múltiplos nos mais diversos campos de estudo a que se dedica a antropologia.

No presente número de Horizontes Antropológicos, a seção Espaço Aberto apresenta uma entrevista com a antropóloga Anna Tsing, um texto de Claudia Fonseca e um texto de Xochitl Marsilli-Vargas. A entrevista com Anna Tsing foi realizada na cidade de Santa Cruz, Califórnia, por Luz Gonçalves Brito, doutoranda do PPGAS-UFRGS, durante o seu estágio de doutorado-sanduíche na Universidade da Califórnia-San Diego. Nessa entrevista, Anna Tsing discorre sobre a sua carreira acadêmica e os seus interesses de pesquisa, apresenta detalhes sobre a trajetória de seu pensamento, aborda conceitos que lhe são caros, tais como Antropoceno, escala e socialidade mais que humana, além de ressaltar a contribuição da pesquisa antropológica na atualidade.

A proposta analítica de Tsing, Mathews e Bubandt (2019) formulada originalmente para o debate sobre Antropoceno é transposta de forma inspiradora para o campo da proteção da infância (em particular a adoção de crianças) por Claudia Fonseca no artigo "Cultivando proliferações indomáveis: considerações antropológicas sobre as políticas de proteção à infância”. No texto, a autora assume um objetivo, um tanto "paradoxal", o de "cultivar o indomável", conferindo visibilidade aos elementos que fogem às simplificações da política formal e enfrentando questões urgentes como a que se coloca em torno do desenvolvimento de pesquisas e formulação de conclusões diante dos cenários problemáticos da atualidade. Diante da lógica simplificada que permeia e orienta as políticas públicas, Fonseca recorre às orientações de Tsing, Mathews e Bubandt, sobretudo à ideia de "proliferações selvagens", para buscar uma ponte possível entre os dados etnográficos (densos e ao mesmo tempo efêmeros e contextualmente situados) e os sistemas abrangentes (com consequências em larga escala e de longo alcance). A autora alia tais reflexões a sua longa e reconhecida trajetória de pesquisa no campo da adoção, para pensar 
caminhos possíveis que mesclem valor, burocracia e emoção. Devido às "proliferações indomáveis", Fonseca nos instiga a refletir sobre as transformações dos atores "pivôs" do processo adotivo e a vislumbrar os espaços "remendados" do sistema de proteção à infância não como problemas, mas sobretudo como "oportunidades produtivas".

Por fim, o artigo "Comunicabilidad y mediatización de los discursos psicoanalíticos en Buenos Aires", de Xochitl Marsilli-Vargas, analisa a circulação de discursos psicanalíticos para além da clínica, através do humor gráfico, de programas de televisão e de anúncios publicitários que circulam em Buenos Aires. Um argumento-chave da análise é que a escuta psicanalítica desempenha um papel importante na disseminação e reprodução na esfera pública de discursos psicanalíticos através da recepção e contínua reciclagem desses discursos por parte do público leigo.

\section{Referências}

CARDOSO DE OLIVEIRA, R. O que é isso que chamamos de antropologia brasileira?. Anuário Antropológico, Brasília, v. 10, n. 1, p. 227-246, 2018. Disponível em: https://periodicos.unb.br/index.php/anuarioantropologico/article/view/6365. Acesso em: 21 jun. 2021.

CIVITAS: Revista de Ciências Sociais. Porto Alegre, v. 13, n. 2, maio/ago. 2013.

COHN, C. A criança, o aprendizado e a socialização na antropologia. In: LOPES DA SILVA, A.; NUNES, A.; MACEDO, A. V. L. da S. (org.). Crianças indígenas: ensaios antropológicos. São Paulo: Fapesp: Global: Mari, 2002. p. 213-235.

COHN, C. Concepções de infância e infâncias. Um estado da arte da antropologia da criança no Brasil. Civitas: Revista de Ciências Sociais, Porto Alegre, v. 13, p. 211-234, 2013.

CUADERNOS DE ANTROPOLOGÍA SOCIAL. Buenos Aires, n. 53, 2021.

DAMATTA, R. Um mundo dividido: a estrutura social dos índios Apinayé. São Paulo: Vozes, 1976.

FONSECA, C. Da circulação de crianças à adoção internacional: questões de pertencimento e posse. Cadernos Pagu, Campinas, v. 26, p. 11-43, 2006. 
HARDMAN, C. Can there be an anthropology of children?. Childhood, [s. l.]. v. 8, n. 4, p. 501-517, 2001.

LATITUDE. Maceió, v. 10, n. 2, 2016.

LOPES DA SILVA, A.; NUNES, A. Introdução: contribuições da etnologia indígena brasileira à antropologia da criança. In: LOPES DA SILVA, A.; NUNES, A.; MACEDO, A. V. L. da S. (org.). Crianças indígenas: ensaios antropológicos. São Paulo: Fapesp: Global: Mari, 2002. p. 11-33.

MEAD, M. Nuestros problemas educativos considerados a la luz de la experiencia samoana. In: MEAD, M. Adolescencia y cultura en Samoa. Buenos Aires: Paidós, 1961. p. 180-219.

MONTERO, P. Antropologia no Brasil: tendências e debates. In: TRAJANO FILHO, W.; RIBEIRO, G. L. (org.). O campo da antropologia no Brasil. Rio de Janeiro: Contra Capa Livraria: Associação Brasileira de Antropologia, 2004. p. 117-142.

POLÍTICA \& TRABALHO: Revista de Ciências Sociais. João Pessoa, ano 32, n. 43, jul./ dez. 2015.

PIRES, F. Ser adulta e pesquisar crianças: explorando possibilidades metodológicas na pesquisa antropológica. In: PIRES, F. Quem tem medo de mal-assombro?: religião e infância no semi-árido nordestino. 2007. Tese (Doutorado em Antropologia Social) - Museu Nacional, Universidade Federal do Rio de Janeiro, Rio de Janeiro, 2007. p. 39-65.

R@U: Revista de @ntropologia da Ufscar. São Carlos, v. 11, n. 1, jan./jun. 2019.

RIBEIRO, F. B. A proibição legal de castigos físicos na infância: alguns contrastes entre Brasil, Uruguai e França. Desidades: Revista Electrónica de Divulgación Científica de la Infancia y la Juventud, Rio de Janeiro, v. 4, n. 10, p. 19-28, 2016. Disponível em: https:// dialnet.unirioja.es/servlet/articulo?codigo=5507518. Acesso em: 27 jun. 2021.

RUNA: Archivo para las Ciencias del Hombre. Buenos Aires, v. 40, n. 2, 2019.

SCHILDKROUT, E. Age and gender in Hausa society: socio-economic roles of children in urban Kano. In: LA FONTAINE, J. S. (ed). Sex an age as principles of social differentiation. London: Academic Press, 1978. p. 109-137.

STRATHERN, M. O gênero da dádiva: problemas com as mulheres e problemas com a sociedade melanésia. São Paulo: Ed. Unicamp, 2006. 
SZULC, A.; COHN, C. Anthropology and childhood in South America: perspectives from Brazil and Argentina. AnthropoChildren, [s. l.], n. 1, 2012. Disponível em: https:// popups.uliege.be/2034-8517/index.php?id=427. Acesso em: 27 jun. 2021.

TASSINARI, A. Concepções indígenas de infância no Brasil. Tellus, Campo Grande, ano 7, n. 13, p. 11-25, out. 2007. Disponível em: http://www.gpec.ucdb.br/projetos/ tellus/index.php/tellus/article/view/138. Acesso em: 27 jun. 2021.

TOREN, C. Making history: the significance of childhood cognition for a comparative anthropology of mind. Man: New Series, [s. l.], v. 28, n. 3, p. 461-478, Sept. 1993.

TSING, A. L.; MATHEWS, A.; BUBANDT, N. Patchy Anthropocene: landscape structure, multispecies history, and the retooling of anthropology. Current Anthropology, [s. l.], v. 60, supl. 20, p. S186-S197, Aug. 2019. 